${ }^{\circledR}$ Entomologica Fennica. 26 October 1998

\title{
Ephestia animella sp. n. (Lepidoptera: Pyralidae, Phycitinae) from the Ural Mountains and southern Siberia
}

\author{
Kari Nupponen \& Jari Junnilainen
}

\begin{abstract}
Nupponen, K. \& Junnilainen, J. 1998: Ephestia animella sp. n. (Lepidoptera: Pyralidae, Phycitinae) from the Ural mountains and southern Siberia. Entomol. Fennica 9: 143-146.

Ephestia animella sp. $\mathrm{n}$. is described from the southern Ural Mountains. It has also been found in the Altai Mountains and Buryatia in southern Siberia. The species occurs in virgin taiga forests from mid-June to early July, and is active only at night. It is a small, dark species that differs from closely related species both externally and by the genitalia. The systematic position of E. animella is discussed.
\end{abstract}

Kari Nupponen, Miniatontie 1 B 9, FIN-02360 Espoo, Finland

Jari Junnilainen, Mahlapolku 3, FIN-01730 Vantaa, Finland

Received 21 May 1997, accepted 21 October 1997

The genus Ephestia Guenée, 1845 contains 10 known species in the Holarctic region. Since Roesler's (1973) revisional work of the Palaearctic Phycitinae, only one new species has been described in this genus: E. columbiella (Neunzig 1990), which occurs in North America. It is the only $E$ phestia species with Nearctic distribution. Two species, E. kuehniella (Zeller, 1879) and E. elutella (Hübner, 1796), are cosmopolitan pests of stored products and the remaining seven occur only in the Palaearctic region.

During the summer of 1996, we explored southern Russia with three Russian and two Finnish colleagues. In the eastern highlands of the southern Ural Mountains we collected several specimens of a small, dark pyralid moth unknown to us. Close examination of the wing venation (Fig. 1) and genitalia showed that this taxon belongs to the genus Ephestia. Roesler (1973) gave the combination of venation characters typical of this genus, which exactly coincides with our species. The main details in venation differentiating Ephestia from closely related genera are in the completely fused veins $R_{3}$ and $R_{4}$ as well as $M_{2}$ and $M_{3}$ of the forewings, $\mathrm{M}_{2+3}$ being separated from $\mathrm{CU}_{1}$ at the base. In the hindwings $\mathrm{M}_{2}$ and $\mathrm{M}_{3}$ are completely fused and separated from $\mathrm{CU}_{1}$, while $\mathrm{SC}$ and $\mathrm{RR}$ stalked at about $60 \%$ of RR length. In the genus Cadra Walker, 1864 the venation is equal, but weak scobinations in the ductus bursae and absence of scale tufts in the female genitalia place the taxon in Ephestia. However, the external appearance and genitalia do not coincide with any known species in the literature.

Ten specimens of this same taxon are included in the collection of the Zoological Museum, University of Helsinki (ZMH), among undetermined material collected from Buryatia and the Altai Mountains in southern Siberia. Mr. Jukka Jalava (pers. comm.) has searched for the species in the collection of the Zoological Institute, St. Petersburg, but without success. In Sinev's (1990) article of the type specimens of the Phycitinae maintained in the Academy of Sciences, St. Petersburg, no mention of Ephestia is present with the exception of E. personata Gerasimov, 1930, which 


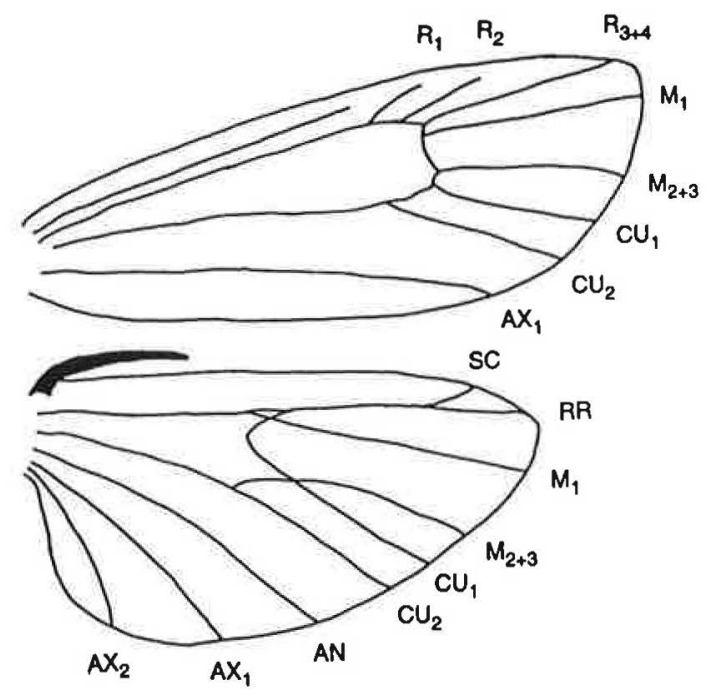

Fig. 1. Wing venation of Ephestia animella sp. $\mathrm{n}$.

Sinev includes in the genus Homoeosoma. Roesler (1973) synonymized E. personata with E. parasitella unicolorella Staudinger, 1881 without examining the holotype. However, the genitalia drawing given by Sinev (1990) shows that personata cannot be included in the genus Ephestia, as Sinev also mentions.

Since it appears that our species is previously unknown, we describe it here under the name Ephestia animella sp. $\mathrm{n}$.

\section{Ephestia animella sp. $\mathrm{n}$.}

Type material. Holotype: $\sigma^{\prime}$ (Fig. 2): Russia, southern Urals, Cheliabinsk district, Iremel Mountain Reserve, 900-1000 m, 25.VI.1996, leg. K. Nupponen, J.-P. Kaitila, J. Junnilainen $\&$ M. Ahola. Paratypes (15 ơ $0^{\prime}, 20$ 우): Same data as holotype, except for dates: 13 ơ O', 17 우 25.VI.1996; $20^{\circ} 0^{\circ}$, 3 우 26.VI.1996. Genitalia slides: K. Nupponen prep. no. 1/14.XII.1996, 2/9.III.1997; 4 further genitalia preparations preserved in glycerol. The holotype is deposited in the private collection of T. \& K. Nupponen. Two of the paratypes, male and female, are in the collection of the $\mathrm{ZMH}$, and the remaining 33 paratypes are in the private collections of T. \& K. Nupponen, J. Junnilainen and J.-P. Kaitila.

Additional material. USSR, SW-Altai, Katun valley 10 W Katanda, 1200 m, 28.VI-05.VII.1983 3 \%우, 06.08.VII.19831 \&, exp. Mikkola, Hippa \& Jalava leg. (ZMH). Russia, Buryatia, $54^{\circ} 52^{\prime} \mathrm{N} 110^{\circ} 55^{\prime} \mathrm{E}$, Barguzin range, $920 \mathrm{~m}$, Olso River valley, taiga, 04.-06.VII.1996 4 070', 2 우, leg. Jalava and Kullberg. (ZMH).

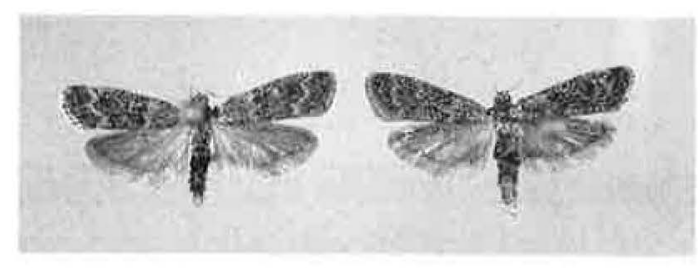

Fig. 2. Ephestia animella sp. n. - Left: male (holotype); - right: female (paratype).

The material from the Altai Mountains and Buryatia is in very poor condition. Most specimens are very worn due to late capture dates, and the forewings have been further chafed during transportation. Furthermore, it is difficult to handle this material without breaking specimens, because they have been dried before pinning. To avoid problems caused by worn paratypes, these specimens are not included in the type material.

Etymology. Lat. animus $=$ spirit. The species is named after the local legend of the Spirit of Iremel, who is said to live on the highest top of the type locality area.

Diagnosis. E. animella is a small, dark species with quite narrow forewings; some fresh specimens are almost black. Antemedial and postmedial lines are distinct and whitish, in contrast to the ground colour of the forewings. Habitually it cannot be confused with any other closely related species. It most resembles $E$. disparella Ragonot, 1901 and dark specimens of $E$. parasitella Staudinger, 1859, but also some northern Eudonia species. In the male genitalia, a strong tooth in the costa of the valva and the shape of the gnathos are very characteristic. E. parasitella is the only Ephestia that has such costal tooth, but it also has culcita. E. inquietella Zerny, 1932 lacks the culcita, but the costal tooth is also absent. In both these species, the gnathos is more slender and more or less sharp at the base, clearly different from that of $E$. animella.

Description. Wingspan 12-15 mm (ơ Ơ12-13 $\mathrm{mm}$, ㅇ 14-15 mm). Head: frons and vertex grey with several whitish-tipped scales; labial palps 1.5-1.75 times the diameter of the eye, curved upward, grey, 1st and 2nd segments with mottled scale tufts ventrally; maxillary palps whitish grey, as long as 3rd segment of labial palps. Male antennae simple, ciliate ( $1 / 3$ of width of shaft). Female 


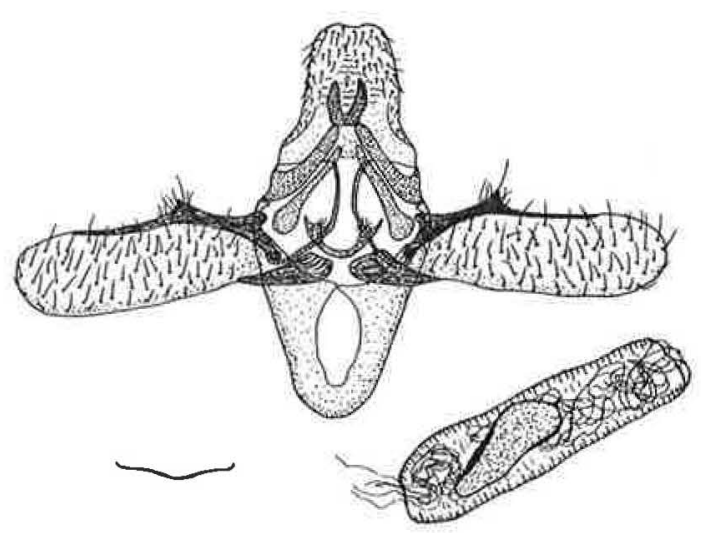

Fig. 3. Male genitalia of Ephestia animella sp. $\mathrm{n}$.

antennae pubescent. Thorax and abdomen grey, more or less mixed paler. Forewing ground colour dark grey to blackish grey, dusted with whitetipped scales; antemedial and postmedial lines sinuous, moderately distinct, whitish; stigmata blackish, indistinct; fringes grey, somewhat paler than ground colour of forewing; male has a small costal fold. Hindwings fuscous with narrow, darker, marginal area and weak suffusion in veins; fringes grey, paler at base, followed by darker fuscous line; discal spots very indistinct.

Male genitalia (Fig. 3). Uncus broad with truncated, slightly concave apex; gnathos robust, bifurcate, straight truncated at base; transtilla incomplete, simple, lower apical part somewhat expanded; anellus wide, flatly U-shaped, lateral lobes triangular; vinculum with rounded apex; valva straight, quite narrow, costa strong with a clear tooth at about 0.3 times distance to apex; sacculus short, tapering towards apex; aedoeagus broad, with large chitinized formation in vesica. Culcita absent.

Female genitalia (Fig. 4). Apophyses posteriores as long as apophyses anteriores; ductus bursae with a band of indistinct, weakly chitinized spines anteriorly; bursa oval, with signum consisting of 5 spines.

Bionomy. Specimens have been observed from late June to early July. E. animella occurs in virgin taiga forests with dominant old trees such as Picea abies, Larix sibirica and Salix caprea, and quite luxuriant lower vegetation, e.g. Aconitum septentrionale. It appears to prefer places with abundant decayed wood and beard moss. All known localities lie at an elevation of 900-1200 m.

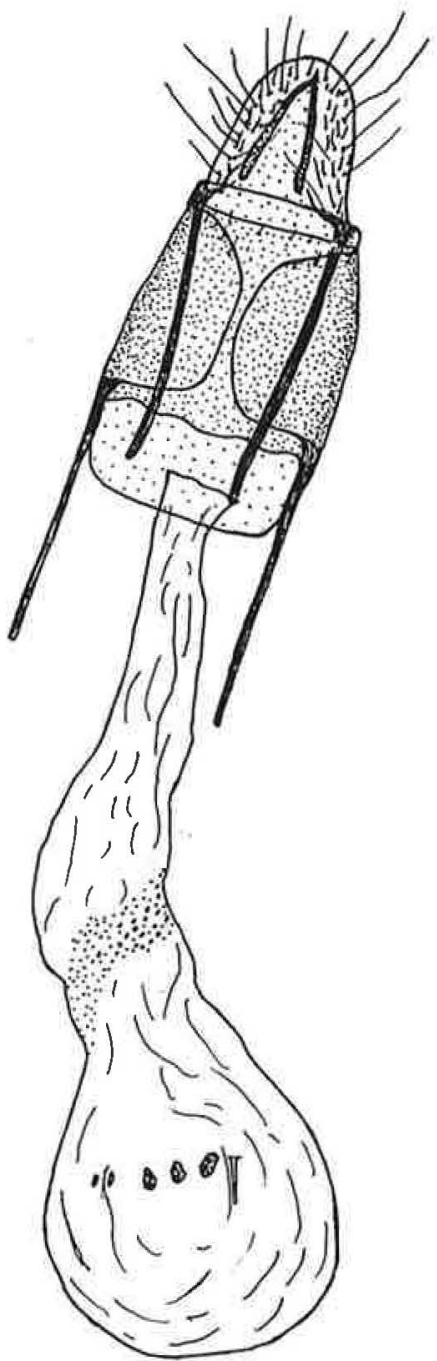

Fig. 4. Female genitalia of Ephestia animella sp. $\mathrm{n}$.

$E$. animella is an early species, because despite the elevation and shady habitat the majority of collected specimens are worn out. The moth flies only at night and comes willingly to artificial light. All attempts to find it in daylight have failed. Immature stages remain unknown.

Distribution (Fig. 5). The species has been found in the easternmost part of Europe, the Iremel Mountains in the southern Ural area, $120 \mathrm{~km}$ north of Magnitogorsk City. Further records are from southern Siberia: Olso River valley in Buryatia, east of Lake Baikal, and Katun valley in the southwestern Altai Mountains. Probably E. animella is widely distributed in the eastern Palaearctic taiga 


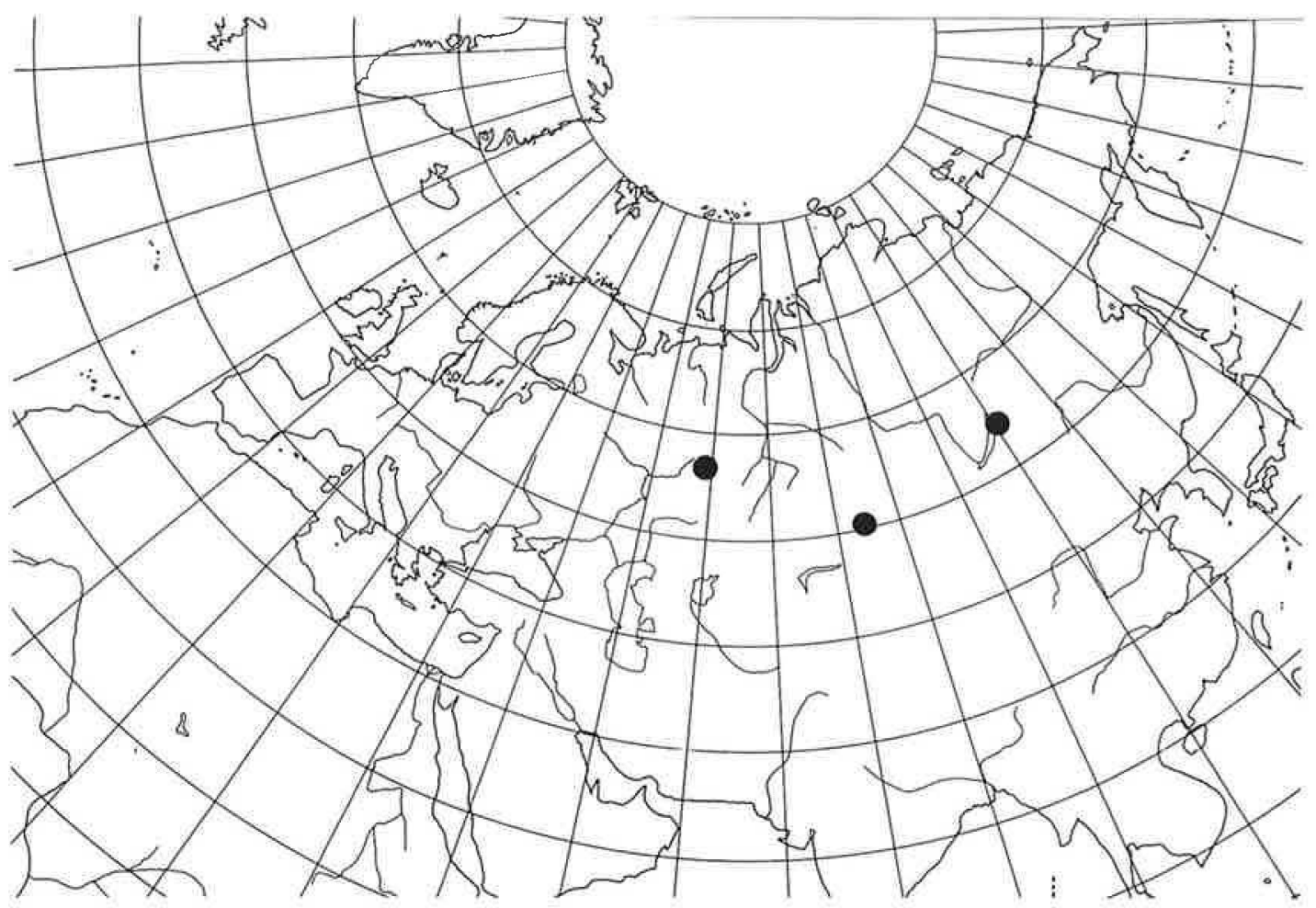

Fig. 5. Distribution of Ephestia animella sp. n.

zone. It is not easy to catch without light, and suitable biotopes are often located at the back of beyond; therefore, the species may have been overlooked.

Remarks. The genus Ephestia has been divided into two subgenera (Roesler 1973). According to the wing venation $E$. animella sp.n. is included in the subgenus Ephestia, because the vein $\mathrm{M}_{2+3}$ is separated from $\mathrm{CU}_{1}$ at the base. Externally E. animella is closest to E. disparella and E. parasitella. In the male genitalia $E$. disparella and $E$. inquietella have very similar straight, narrow valvae, as does E. animella. E. inquietella also lacks the culcita as well as $E$. animella. However, the most characteristic feature in E. animella is a strong tooth in the costa of the valva. To date, only one other known species with such tooth occurs in the genus Ephestia, E. parasitella. In the female genitalia, similar chitinized bands are present in the ductus bursae in $E$. parasitella and E. animella. Thus, the systematic position of $E$. animella is placed near E. parasitella, which is its closest relative.
Acknowledgements. We thank Dr. Vladimir Olshvang (Ekaterinburg, Russia) for organizing the southern Ural expedition and the following accompanying colleagues: Mr. Yuri Mikhailov (Novouralsk, Russia), Mr. Alexander Malozemov (Ekaterinburg, Russia), Mr. Jari-Pekka Kaitila (Vantaa, Finland) and Mr. Matti Ahola (Hämeenkoski, Finland). Our thanks are also due to Mr. Jukka Jalava (Helsinki, Finland) for the loan and comments on the Siberian Ephestia material. Finally, we thank Mr. Reino Tyynelä (Helsinki, Finland) for his help in processing the photograph.

\section{References}

Neunzig, H. H. 1990: Pyraloidea, Pyralidae (part). — In: Dominick, R. B., Davis, D. R., Dominick, T., Ferguson, D. C., Hodges, R. W., Munroe, E. G. \& Powell, J. A. (eds.), The Moths of America North of Mexico, fasc. 15.3.

Roesler, R.-U. 1973: Phycitinae: Trifine Acrobasiina 1. In: Amsel, H.G., Gregor, F. \& Reisser, H. (eds.), Microlepidoptera Palearctica 4, Teil I: 752 pp; II: 138 pp + 170 plates. Wien.

Sinev, S. Y. 1990: Type Specimens of the Phycitidae (Lepidoptera) kept in the Collection of the Zoological Institute of the Academy of Sciences of the USSR. 2. Entomologiceskoc Obozrenie 69(2): 419-431. (In Russian.) 